\title{
Etiologic characterization of vulvovaginitis among females attending a tertiary care hospital: a one year study
}

\author{
Chembetei Kavitha Kiran $^{1 *}$, Jithendra Kandati ${ }^{2}$, Munilakshmi Ponugoti ${ }^{2}$
}

\begin{abstract}
${ }^{1}$ Department of Obstetrics and Gynecology, ${ }^{2}$ Department of Microbiology, Narayana Medical College, Nellore, Andhra Pradesh, India
\end{abstract}

Received: 19 April 2017

Accepted: 24 April 2017

\author{
*Correspondence: \\ Dr. Chembetei Kavitha Kiran, \\ E-mail: sujatha2481@gmail.com
}

Copyright: (c) the author(s), publisher and licensee Medip Academy. This is an open-access article distributed under the terms of the Creative Commons Attribution Non-Commercial License, which permits unrestricted non-commercial use, distribution, and reproduction in any medium, provided the original work is properly cited.

\begin{abstract}
Background: Vulvovaginitis is one among the major pathologies encountered in reproductive age group. Etiologies are always multiple and candidiasis, bacterial vaginitis and trichomoniasis account for $90 \%$ of etiology. The incidence is dependable upon multiple factors like age group, ethnicity, socioeconomic status, geographical locale. Improperly treated and untreated vulvovaginitis is associated with long term complications like infertility, pelvic inflammatory disease in nulliparous females and preterm labour, miscarriage, ectopic pregnancy, chorioamnionitis among pregnant females and recurrent UTIs, cervicitis, endometritis, increased risk of acquiring STIs among normal females. The present study was undertaken with the objective of understanding the etiologies associated with vulvovaginitis among women attending Obstetrics clinic of a tertiary care hospital. The risk factors associated with the conditions, the features of the vaginal discharge and symptoms associated with each etiology were studied.

Methods: A cross sectional study for a period of one year was conducted among 200 female patients attending the Department of gynecology for vaginitis and evaluated for etiology. Patient's risk factors, clinical history, symptoms were collected by questionnaire and specimens were collected from all the cases and processed as per standard guidelines. Bacterial vaginosis was confirmed based on Neugent's criteria, Trichomoniasis by wet mount examination and candidiasis by culture. The study was approved by the institutional ethical committee.

Results: 137 cases of vulvovaginitis were diagnosed based on etiology. Vulvovaginitis was most common among 27 36 years and in multiparous women. Most common causative agent was Candida (59.12\%) followed by bacterial vaginosis $(22.63 \%)$ and Trichomoniasis (18.25\%). Vaginal discharge was the commonest symptom (100\%) followed by malodor and vulval irritation. Following unhygienic practices was the commonest risk factor associated with Vulvovaginitis.

Conclusions: A regular evaluation is mandatory for all the females attending hospital for vaginitis. Successful management reduces the morbid conditions and it's essential to treat the conditions during the pregnancy which prevents the complications associated like preterm birth, miscarriage etc. and adverse outcomes.
\end{abstract}

Keywords: Bacterial vaginosis, Candidiasis, Trichomoniasis, Vulvovaginitis

\section{INTRODUCTION}

Reproductive tract infections including sexually transmitted infections are most common infections seen among women in fertile age group, pregnant and pre- menopausal age. These infections are associated with severe morbidity among fertile group and adverse outcomes in pregnant females. ${ }^{1}$ The female genital tract acts as a major portal of entry for many pathogens causing sexually transmitted diseases. Vulvovaginitis is 
one among the major pathologies encountered in reproductive age group. Etiologies are always multiple and candidiasis, bacterial vaginitis and trichomoniasis account for $90 \%$ of etiology. ${ }^{2}$

The incidence is dependable upon multiple factors like age group, ethnicity, socioeconomic status, geographical locale. The symptoms predominantly associated with vulvovaginitis include vaginal discharge, vulval itching and malodor depending upon the etiology. However, few of the cases are asymptomatic in case of bacterial vaginosis. ${ }^{3}$ Most of the symptoms are nonspecific and diagnosis without laboratory confirmation may lead to inappropriate management and complications. Improperly treated and untreated vulvovaginitis is associated with long term complications like infertility, pelvic inflammatory disease in nulliparous females and preterm labour, miscarriage, ectopic pregnancy, chorioamnionitis among pregnant females and recurrent UTIs, cervicitis, endometritis, increased risk of acquiring STIs among normal females. ${ }^{4}$

Knowing the knowledge in prevalence of most common etiology of vulvovaginitis helps in reducing the complications with early intervention and management. The present study was undertaken with the objective of understanding the etiologies associated with vulvovaginitis among women attending a tertiary care hospital. The risk factors associated with the conditions, the features of the vaginal discharge and symptoms associated with each etiology were studied.

\section{METHODS}

A prospective cross sectional study was conducted at Narayana medical college a tertiary care hospital, among female patients attending the Department of Obstetrics \& Gynecology, Department of Venereology in association with Department of Microbiology. The study period was one year from December 2015 to November 2016. 200 patients who fulfilled the inclusion criteria and willing to participate in the study were enrolled. Patient's demographic data, Risk factors, Clinical history, clinical symptoms and signs were noted in a separate case questionnaire form. Approval for the study was granted by the institutional ethics committee.

\section{Inclusion criteria}

- Cases of age 16-50 years attending the Department of Gynecology and Department of Venereology

- Cases willing for speculum examination.

\section{Exclusion criteria}

- Cases that were on antibiotics 4 weeks prior or at present

- Cases not consented for the study

- Pregnant cases and cases on Menstruation.

\section{Specimen collection and processing}

Three sterile cotton swabs were taken and inserted per vaginally and material was collected from the lateral wall of the vagina (High vaginal Swabs) These swabs were immediately sent to Microbiology Laboratory for further processing.

The first swab was used to determine the vaginal $\mathrm{pH}$ by using a $\mathrm{pH}$ paper strip and comparing with the reference standards. The smear was prepared from the swab, gram stained and finally 2 drops of $10 \% \mathrm{KOH}$ were added to determine the amine odor (Whiff test). The gram stained slide was evaluated by Neugent's scoring system for detection of Bacterial vaginosis. A score of $0-3$ was interpreted as negative, 4-6 as intermediate and 7-10 as positive. ${ }^{5}$ The second swab was placed in a test tube containing $0.5 \mathrm{ml}$ of $0.9 \%$ saline and performed wet mount examination on a clean glass slide. The swab was vigorously rotated and expressed fluid from the swab was placed on a slide and examined under low power objective of the microscope and examined for trichomonas vaginalis. The parasite was identified by its characteristic morphology and jerky motility. The third swab was inoculated onto Sabourad's dextrose agar with antibiotics and incubated at $370 \mathrm{c}$ for $48 \mathrm{hrs}$ for isolation of Candida sp. The species were identified as albicans and non albicans group based on germ tube formation and chlamydospore formation.

\section{Blood tests}

$5 \mathrm{ml}$ of blood was collected and performed following tests

- $\quad$ HIV antibody test by Tri-dot ICT test. J. Mithra and Co., Ltd.

- RPR for syphilis was done by slide agglutination test. Span Diagnostics, Ltd.

\section{Statistical analysis}

The data of the study was entered in microsoft excel sheet by trained Health care workers and analyzed. Descriptive analysis was performed for all variables and data presented as percentages. A p value $<0.05$ was considered significant.

\section{RESULTS}

Out of 200 females who participated in the study, all the participants were screened for HIV and Syphilis. Demographic data of the cases were recorded and history of risk factors like sexual partners, old H/O of STDs etc was recorded. Clinical history, clinical signs and symptoms of the cases positive for vaginosis were recorded. Etiology was recorded as bacterial vaginosis, candidiasis, trichomoniasis, HIV and syphilis. Other associated STI like chlamydiasis, HSV infections could not be evaluated due to lack of facilities. Majority of study group (44\%) were between 27-36 years of age, 
$38 \%$ between $37-47$ years and $18 \%$ between $16-26$ years. The median age of the study population was 35 years (Interquartile range, 30-43 years). 72 (36\%) of the participants were nulliparous, $58(29 \%)$ were primiparous and $70(35 \%)$ were multiparous (Table 1$)$.

Table 1: Demographic data of cases in study.

\begin{tabular}{|lll|}
\hline \multicolumn{2}{|l|}{ Number } & Percentage \\
\hline Age & 27 & 19.71 \\
\hline $16-26$ & 58 & 42.34 \\
\hline $27-36$ & 52 & 37.96 \\
\hline $37-47$ & & \\
\hline Parity & 27 & 13.5 \\
\hline Nulliparous & 49 & 24.5 \\
\hline Primi & 61 & 30.5 \\
\hline Multi & \\
\hline Diagnosis & 25 & 18.25 \\
\hline Trichomoniasis & 31 & 22.63 \\
\hline Bacterial vaginosis & 81 & 59.12 \\
\hline Candidiasis & 61 & 75.31 \\
\hline C. albicans & 20 & 24.69 \\
\hline NAC $($ Non albicans candida) & & \\
\hline Others & 20 & 14.6 \\
\hline HIV alone & 28 & 20.44 \\
\hline Syphilis Alone & 8 & 5.84 \\
\hline Both HIV and Syphilis & & \\
\hline
\end{tabular}

Out of 200 participants, total of 137 (68.5\%) were diagnosed with vulvovaginitis. Out of 137 cases, $42.34 \%$ (58) were between 27-36 years of age, $37.96 \%$ (52) were of 37-47 years of age and $19.71 \%$ (27) were of $16-26$ years of age (Table 2).

Out of 137 confirmed cases of vaginosis, 28 were HIV positive, 36 were positive for syphilis and 8 were positive for both HIV and syphilis. The risk factors of the cases were evaluated and vaginosis is maximum among cases following unhygienic practices $(71.53 \%)$ followed by cases following contraceptive practices $(64.23 \%)$.

Multiple sexual partners $(55.47 \%)$ and least $(8.76 \%)$ in cases with douching and with H/o Antibiotic administration ( $>2$ weeks). Other associated risk factors were menstrual irregularities, old $\mathrm{H} / \mathrm{O}$ of STDs and diabetes (Table 3).

The most common presenting symptom was vaginal discharge which was observed in all the cases (100\%). The features of the discharge with regard to duration, color, consistency, quantity, and $\mathrm{pH}$ are described in Table 4

In 107 cases the duration of discharge was $\leq 15$ days and 30 cases $>15$ days. 62 cases of candidiasis had duration $\leq 15$ days and 19 cases $>15$ days.

Table 2: Age wise distribution of cases of vaginitis.

\begin{tabular}{|lllll|}
\hline Age group & Trichomoniasis $(\%)$ & Bacterial vaginosis $(\%)$ & Candidiasis $(\%)$ & Total $(\%)$ \\
\hline 16-26 years & 8 & 8 & 11 & $27(19.71)$ \\
\hline $27-36$ years & 6 & 14 & 38 & $58(42.34)$ \\
\hline $37-47$ years & 11 & 9 & 32 & $52(37.96)$ \\
\hline Total & $25(18.25)$ & $31(22.63)$ & $81(59.12)$ & 137 \\
\hline
\end{tabular}

Table 3: Risk factors for vulvo vaginitis.

\begin{tabular}{|lll|}
\hline Risk factor & Number & Percentage \\
\hline Unhygeine practices & 98 & 71.53 \\
\hline Douching & 12 & 8.76 \\
\hline Menstrual irregularities & 34 & 24.82 \\
\hline Multiple sexual partners & 76 & 55.47 \\
\hline Old h/o of STD & 28 & 20.44 \\
\hline Diabetes & 42 & 30.66 \\
\hline $\begin{array}{l}\text { H/o antibiotic administration } \\
\text { (>2 weeks) }\end{array}$ & 12 & 8.76 \\
\hline Contraceptive practices & 88 & 64.23 \\
\hline
\end{tabular}

Consistency of the discharge was thin in 52 cases and 85 cases had thick consistency. In cases of bacterial vaginosis all cases had thin consistency, 17 cases in trichomoniasis whereas 77 cases in cases of candidiasis had thick consistency. Significant association between color of discharge and etiology was noted. Majority of cases of candidiasis (66.67\%) had thick white creamy curd like discharge, in cases of Bacterial vaginosis white colored discharge was seen in $77.42 \%$ of cases and green colored discharge in $76 \%$ of cases of trichomoniasis. In $83.95 \%$ of cases of candidiasis $\mathrm{pH}$ of the discharge was $\leq 5$ whereas in $100 \%$ of cases of bacterial vaginosis and $92 \%$ of cases of trichomoniasis the $\mathrm{pH}$ was $>5$. Malodor was seen in $64 \%$ of cases of trichomoniasis, $54.32 \%$ of cases of candidiasis and $38.71 \%$ cases of bacterial vaginosis. Vulval itching was seen in $96.3 \%$ of cases of candidiasis, $80 \%$ of trichomoniasis and $70.97 \%$ in bacterial vaginosis. Dyspareunia and dysuria was most commonly associated with candidiasis than the other conditions. Pain abdomen was associated with bacterial vaginosis than candidiasis and trichomoniasis. Genital ulcers were noted in 12 cases of syphilis positive cases and multiple warts were noted in 8 HIV positive cases. The features of vaginal discharge and symptoms in association with etiology from 137 cases are presented in Table 5. 
Table 4: Characteristic features of vaginal discharge and symptoms.

\begin{tabular}{|llll|}
\hline Duration & Candidiasis $(n=81)$ & Bacterial vaginosis $(n=31)$ & Trichomoniasis $(n=25)$ \\
\hline$\leq 15$ days & 62 & 24 & 21 \\
\hline$>15$ days & 19 & 7 & 4 \\
\hline Consistency & & & \\
\hline Thin & 4 & 31 & 8 \\
\hline Thick & 77 & & \\
\hline Colour & & 27 & 0 \\
\hline White & 27 & 2 & 3 \\
\hline White curdy & 54 & 0 & 3 \\
\hline Cream & 0 & 2 & 19 \\
\hline Greenish & 0 & & 2 \\
\hline Ph & & 0 & 23 \\
\hline$\leq 5$ & 68 & 31 & 8 \\
\hline >5 & 13 & & 17 \\
\hline Quantity & & 10 & 16 \\
\hline Scanty & 54 & 21 & 20 \\
\hline Copious & 27 & 12 & 3 \\
\hline Malodour & 44 & 22 & 3 \\
\hline Vulval itching & 78 & 14 & 8 \\
\hline Pain abdomen & 22 & 4 & \\
\hline Dysuria & 32 & 2 & \\
\hline Dyspareunia & 64 & & \\
\hline
\end{tabular}

Table 5: Characteristic features of symptoms with etiology.

\begin{tabular}{|c|c|c|c|}
\hline & Candidiasis ( $n=81$ ) & Bacterial Vaginosis $(n=31)$ & Trichomoniasis ( $n=25$ ) \\
\hline & Number (\%) & Number (\%) & Number (\%) \\
\hline \multicolumn{4}{|l|}{ Duration } \\
\hline$\leq 15$ days & $62(76.54)$ & $24(77.42)$ & $21(84)$ \\
\hline$>15$ days & $19(23.46)$ & $7(22.58)$ & $4(16)$ \\
\hline \multicolumn{4}{|l|}{ Consistency } \\
\hline Thin & $4(4.94)$ & $31(100)$ & $17(68)$ \\
\hline Thick & $77(95.06)$ & & $8(32)$ \\
\hline \multicolumn{4}{|l|}{ Colour } \\
\hline White & $27(33.33)$ & $27(77.42)$ & 0 \\
\hline White curdy & $54(66.67)$ & $2(6.45)$ & $3(12)$ \\
\hline Cream & 0 & 0 & $3(12)$ \\
\hline Greenish & 0 & $2(6.45)$ & $19(76)$ \\
\hline \multicolumn{4}{|l|}{$\mathbf{P h}$} \\
\hline$\leq 5$ & $68(83.95)$ & 0 & $2(8)$ \\
\hline$>5$ & $13(16.05)$ & $31(100)$ & $23(92)$ \\
\hline \multicolumn{4}{|l|}{ Quantity } \\
\hline Scanty & $54(66.67)$ & $10(32.26)$ & $8(32)$ \\
\hline Copious & $27(33.33)$ & $21(67.74)$ & $17(68)$ \\
\hline Malodour & $44(54.32)$ & $12(38.71)$ & $16(64)$ \\
\hline Vulval itching & $78(96.3)$ & $22(70.97)$ & $20(80)$ \\
\hline Pain abdomen & $22(27.16)$ & $14(45.16)$ & $3(12)$ \\
\hline Dysuria & $32(39.51)$ & $4(12.9)$ & $3(12)$ \\
\hline Dyspareunia & $64(79.01)$ & $2(6.45)$ & $8(32)$ \\
\hline
\end{tabular}

Out of 137 diagnosed cases of Vulvovaginitis, candidiasis was the most common etiology with $59.12 \%$, followed by bacterial vaginitis $22.63 \%(\mathrm{n}=31)$ and $18.25 \%(\mathrm{n}=25)$ were diagnosed with Ttrichomoniasis. 6 cases were co infected with both vaginal candidiasis and bacterial vaginitis. In cases of vulvovaginal candidiasis, most 
common etiological agent was $C$. albicans isolated from 61 cases $(75.31 \%)$ and Non albicans candida (NAC) from 20 cases $(24.69 \%)$. Among NAC cases, $C$. tropicalis (14) and $C$. krusei (6) were isolated. Bacterial vaginosis was confirmed in $31 / 137(22.63 \%)$ cases by Nugent's scoring $\geq 7$.

\section{DISCUSSION}

Vaginitis is one of the commonest reproductive tract infections associated with significant morbidity. Etiologies associated with vaginitis are multiple and establishing the etiology helps in successful management and prevention of complications. ${ }^{6}$ the prevalence of vulvovaginitis in our study was $68.5 \%$ which is in accordance with the findings of Sharma VK et al. ${ }^{7}$ Various studies estimate the prevalence rates range from $2.5 \%$ to $48 \% .^{8}$ But the prevalence rates are always dependable upon multiple factors like group involved, educational status, economic background, detection techniques and geographical locale etc.

In present study, for some of the cases the etiology was undefined which indicates the role of viruses in infectious vaginitis. In the present study, the commonest age group was sexually active age 27-36 years which coincides with the findings of Sharma AK et al Unhygienic practices and illiteracy are associate risk factors in our study associated with vulvovaginitis. ${ }^{9}$ Other associated risk factors were contraceptive practices followed which in our study are mostly irregular administration of OCPs and IUCDs.

The possible explanation could be increased duration of bleeding period and bleeding which in illiterate women increased unhygienic practices leading to vulvovaginitis. Douching was a good practice and vulvovaginitis was observed less commonly in cases following douching and Bacterial vaginosis was less common in patients who had history of antibiotic administration. These findings were on par with findings of many studies. ${ }^{10}$ Vaginal discharge was the commonest complaint mentioned in our study. Other less associated complaints were dyspareunia, abdominal pain. Vulvovaginitis is most commonly observed in multiparous women than in nulliparous and primiparous women. This was observed in our study which coincides with the findings of Nurat AA et al who reported the prevalence of $36 \%$ in his studies which is in accordance with $30.5 \%$ in our study. ${ }^{11}$

Vaginal discharge was the commonest complaint in our study as mentioned by the studies in India and globally. ${ }^{12,13}$ However, the nature of the discharge and characteristics are variable depending upon the etiological condition. Vulvovaginal candidiasis is commonly associated with thick, white curd like discharge, malodoured and its association was statistically significant. ( $P$ value $<0.001$ ) In cases of trichomoniasis, thin, green colored discharge and complaining of dyspareunia, vulval irritation was most common and statistical significance was associated with green colored discharge and vulval irritation ( $\mathrm{p}$ value $<0.001$ ). In bacterial vaginosis thin, white colored discharge with associated pain abdomen was commonly associated and was found statistically significant. These findings of our study correlate with the findings of many studies and suggest possible co infections with mixed symptoms and signs..$^{14}$

Our study informs that signs and symptoms are always not specific and hence identification by wet mount for trichomoniasis, Neugent's scoring for Bacterial vaginosis and culture for Candida for identification up to species level are important in confirmation and management of vulvovaginitis. ${ }^{15}$ In present study the most common etiology was Candidiasis as mentioned in various studies globally. Among the candida, still $C$. albicans is the most common agent. However, few studies reported the increasing prevalence of Non albicans Candida (NAC) from cases associated with immunosuppression and associated sexually transmitted infections. ${ }^{16}$ Increasing trends in development of resistance among candida is noticed because of wide prescription of azole compounds, hence it's imperative to identify the species and perform antifungal susceptibility among isolates of vulvovaginal candidiasis.

The prevalence of bacterial vaginosis in our study was $22.63 \%$ which correlates with the prevalence of Madhivanan P et al, Mathew R et al and Allsworth JE. ${ }^{17-}$ 19

Most common symptoms of bacterial vaginosis in our study was thin, copious white colored discharge with $\mathrm{pH}$ $>5$. Statistical significance was associated with thin discharge and vulval irritation and pain abdomen. These findings of our study are in accordance with the findings of Fethers KA et al and Bahram A et al. ${ }^{20,21}$ Prevalence of Trichomoniasis in our study was $18.25 \%$ which is low when compared with findings of Kadir et al who reported prevalence of $28 \%$ in his study. $^{22}$ Most common symptoms associated are thin green colored discharge with $\mathrm{pH}>5$, Discharge was malodoured and Vulval itching was the found to be associated commonly. Findings of our study was consistent with the reports of S $\mathrm{R}$ Fule et al, Madhivanan $\mathrm{P}$ et al, and Mason $\mathrm{P} \mathrm{R}$ et al. ${ }^{23-25}$ These differences in variation may be due to variations in personal hygiene, environment and socio economic conditions which vary from place to place.

\section{CONCLUSION}

To conclude our study characterized the etiology of vulvovaginitis among women attending a tertiary care hospital. The most common etiology was candidiasis and age group was 26-36 years of age. Other etiologies noted were trichomoniasis and bacterial vaginosis.

A regular evaluation is mandatory for all the females attending hospital for vaginitis. Successful management reduces the morbid conditions and its essential to treat the 
conditions during the pregnancy which prevents the complications associated like preterm birth, miscarriage etc. and adverse outcomes.

Funding: No funding sources

Conflict of interest: None declared

Ethical approval: The study was approved by the Institutional Ethics Committee

\section{REFERENCES}

1. Philip PS, Benjamin AI, Sengupta P. Prevalence of symptoms suggestive of reproductive tract infections/sexually transmitted infections in women in an urban area of Ludhiana. Indian J Sex Transm Dis. 2013;34(2):83-8.

2. Bohbot JM, Sednaoui P, Verriere F, Achhammer I. The etiologic diversity of vaginitis. Gynecologie, Obstetrique Fertilite. 2012;40(10):578-81.

3. Sobel JD. Vulvovaginal candidosis. The Lancet. 2007;369(9577)1961-71.

4. Moodley P, Connolly C, Sturm AW. Interrelationships among human immunodeficiency virus type 1 infection, bacterial vaginosis, trichomoniasis, and the presence of yeasts. J Infect Dis. 2002;185(1)69-73.

5. Nugent RP, Krohn MA, Hillier SL. Reliability of diagnosing bacterial vaginosis is improved by a standardized method of gram stain interpretation. J Clini Microbiol. 1991;29(2):297-301.

6. McCormack Jr WM, Zinner SH, McCormack WM. The incidence of genitourinary infections in a cohort of healthy women. Sex Transm Dis. 1993;21(2):63-4.

7. Sharma VK, Khandpur S. Epidemiology of sexually transmitted diseases. In: Sharma VK, editor. SexuallyTransmitted Diseases and AIDS. New Delhi: Viva Books Pvt Ltd;2003:11-2.

8. Mulu W, Yimer M, Zenebe Y, Abera B. Common causes of vaginal infections and antibiotic susceptibility of aerobic bacterial isolates in women of reproductive age attending at Felegehiwot referral Hospital, Ethiopia: a cross sectional study. BMC Women's Health. 2015;15(1):42.

9. Sharma AK, Ranjan R, Mehtha G. Prevalence and determinants of reproductive tract infections among Women. J Commun Dis. 2004;36:93-9.

10. Hutchinson KB, Kip KE, Ness RB. Vaginal douching and development of bacterial vaginosis among women with normal and abnormal vaginal microflora. Sex Transm Dis. 2007;34:671-5.

11. Nurat AA, Bahalola GO, Shittu MO, Tijani AM, Adekola SA. Detection and epidemiology of vulvovaginal candidiasis among asymptomatic pregnant women attending a tertiary hospital in Ogbomoso, Nigeria. Int J Biomed Res. 2015;6:518-23.

12. Mulu W, Yimer M, Zenebe Y, Abera B. Common causes of vaginal infections and antibiotic susceptibility of aerobic bacterial isolates in women of reproductive age attending at Felegehiwot referral Hospital, Ethiopia: A cross sectional study. BMC Womens Health. 2015;15:42.

13. Wang J. Bacterial vaginosis. Prim Care. 2000;7:181-5.

14. Gupta G, Nandwani S, Agarwal A. Prevalence of candidiasis, trichomoniasis and bacterial vaginosis among women of reproductive age group. Indian $\mathbf{J}$ Public Health Res Dev. 2013;4(2):94.

15. Schaaf VM, Perez-Stable EJ, Borchardt K. The limited value of symptoms and signs in the diagnosis of vaginal infections. Arch Intern Med. 1990;150:1929-33.

16. Jithendra K, Madhavulu B, Mohan PR, Munilakshmi P, Avinash G. Candida speciation from vaginal candidiasis and its antifungal susceptibility. Int J Curr Med Appl Sci. 2015;5 (3):144-8.

17. Madhivanan P, Krupp K, Chandrasekaran V, Karat C, Arun A, Cohen CR ET AL. Prevalence and correlates of bacterial vaginosis among young women of reproductive age in Mysore, India. Indian $\mathrm{J}$ Med Microbiol. 2008;26(2):132.

18. Mathew R, Sudhakshina R, Kalyani M, Jayakumars S, Lai B, Banu S. Microbiological profile of vaginosis among women of the reprioductive age group, who attended a tertiary care Hospital. JCDR. 2011;8(5):1548-51

19. Allsworth JE, Peipert JF. Prevalence of bacterial vaginosis: 2001-2004 National Health and Nutrition Examination Survey Data. Obstet Gynecol. 2007;109(1):114-20.

20. Fethers KA, Fairley CK, Hocking JS et al. Sexual risk factors and bacterial vaginosis: a systematic review and meta-analysis. Clin Infect Dis. 2008;47:1426-35.

21. Bahram A, Hamid B, Zohre T. Prevalence of bacterial vaginosis and impact of genital hygiene practices in non-pregnant women in Zanjan, Iran. Oman Med J. 2009;24(4):288-93

22. Kadir MA, Sulyman MA, Dawood IS, Shams-Eldin S. Trichomonas vaginalis and associated microorganisms in women with vaginal discharge in Kerkuk-Iraq. Ankara Med J. 2014;14(3).

23. Fule SR, Fule RP, Tankhiwale NS. Clinical and laboratory evidence of Trichomonas vaginalis infection among women of reproductive age in rural area. Indian J Med Microbiol. 2012;30(3):314.

24. Madhivanan P, Bartman MT, Pasutti L, Krupp K, Arun A, Reingold AL, Klausner JD. Prevalence of Trichomonas vaginalis infection among young reproductive age women in India: implications for treatment and prevention. Sex health. 2009;6(4):339-44.

25. Mason PR, Super H, Fripp PJ. Comparison of four techniques for the routine diagnosis of Trichomonas vaginalis infection. J Clin Pathol. 1976;29(2):154-7.

Cite this article as: Kiran CK, Kandati J, Ponugoti M. Etiologic characterization of vulvovaginitis among females attending a tertiary care hospital: a one year study. Int J Reprod Contracept Obstet Gynecol 2017;6:2246-51. 